\title{
Deaths in three accident and emergency departments
}

\author{
M. W. BECKETT, ${ }^{1}$ P. M. LONGSTAFF, ${ }^{2 *}$ M. J. McCABE, ${ }^{3}$ \\ D. A. SULCH ${ }^{4}$ AND M. J. WARD ${ }^{4}$
}

${ }^{1}$ Accident and Emergency Department, West Middlesex University Hospital, ${ }^{2}$ Accident and Emergency Department, St Stephen's Hospital, ${ }^{3}$ Accident and Emergency Department, Northwick Park Hospital, and ${ }^{4}$ St Mary's Hospital Medical School, Middlesex, England

\section{SUMMARY}

A survey of three London hospitals found that approximately 0.45 patients per thousand new attenders die in the accident and emergency department and that there is evidence of poor management in about $10 \%$ of these deaths. The commonest faults were excessive delay before starting appropriate treatment and neglect of the basic principles of emergency medicine. These points need to be emphasized in the training of accident and emergency staff.

\section{INTRODUCTION}

Many critically ill patients are brought to the accident and emergency (A \& E) department, not only as a result of trauma, but also due to acute or chronic illness. Inevitably, some die there: the number that do so will reflect, in part, patterns of mortality and the use of the A \& E service by the community. However, the total will also be influenced by standards of nursing and medical care.

A previous survey reported deaths in a Birmingham $\mathrm{A} \& \mathrm{E}$ department in the years 1978-82 (Shalley \& Cross, 1984). During this period, 488 deaths occurred in a department which saw 54000 new patients per year. An analysis was made of the causes of death but no comment was made on the number of these deaths that might have been avoided by improved medical care.

The authors examined all deaths which occurred in 1984 in the A \& E departments of three West London hospitals: St Stephen's Hospital, Fulham; the Central Middlesex

*Currently Senior Registrar in Emergency Medicine, Ealing Hospital, Southall, Middlesex, England.

Correspondence: $\operatorname{Dr}$ M. W. Beckett, West Middlesex University Hospital, lsleworth, Middlesex TW7 $6 A F$, England. 
Hospital, NW 10; and Northwick Park Hospital, Harrow. The authors have attemptedi霄 to assess the accuracy of the casualty officer's initial diagnosis and whether anys alternative management might have prevented death.

It is a frequent occurrence that patients are brought to the $\mathrm{A} \& \mathrm{E}$ departmen unconscious with a history of sudden collapse. They are found to have no detectable cardiac output and cardiopulmonary resuscitation is started immediately. After some time, it is decided that there has been no response and the patient is certified as dead. I is impossible to decide with any precision whether death actually occurred in the A \& $\mathrm{E}_{\square}^{\mathrm{D}}$ department or before arrival. Therefore, for the purpose of this study, the authors hav considered only patients who are known to have been alive on arrival: all were recordeळ by a doctor or nurse to have had a measurable pulse or blood pressure or to have beenconscious at some time in the department. It is unusual for a patient to be revived after being brought in with none of these vital signs present.

\section{METHOD}

By inspection of the A \& E registers, the authors identified all patients who were alive्⿱ initially and then transferred from the department to the mortuary: that is, those whơ died in the department. Included among these were some who had been admitted at the request of their general practitioners and were waiting in the A \& E Department for a bed on the wards. From the A \& E record cards of all those who were alive when figsto seen, the following information was extracted:

(1) the age of the patient;

(2) the initial working diagnosis where this is stated or, if not stated, implied by the recorded findings and the treatment given (in some cases, it is not possible to say $\overrightarrow{0}$ what diagnosis; if any, was arrived at and the authors have, therefore, recorded it as 'unclear');

(3) the time interval between the patient entering the department and being seen by $a^{\frac{\Phi}{3}}$ doctor (in some instances, the latter time was not recorded: an omission more likelyo when the urgency of the case is obvious);

(4) the time interval between the patient entering the department and the time death is pronounced;

(5) whether a decision was made or implied before death that an attempt at resusci tation would be inappropriate: for example, due to severe progressive illness or disability.

Additionally, the clinical diagnosis was compared with the post-mortem diagnosis where this was available. Post-mortem examinations were performed in $70 \%$ of cases following referral to Her Majesty's Coroner. 


\section{RESULTS}

Table 1 shows the number of deaths occurring in each department and the ages of the patients. It is seen that many of the patients are elderly, as was noted in the Birmingham study in which $66 \%$ of the patients who died were over 60 years.

Table 2 shows the certified cause of death for each case, using the post-mortem information where available.

Table 3 tabulates the time interval between admission and when the patient was recorded as having seen a doctor, and the time before death was diagnosed. It will be seen that, especially in hospital 1 , the casualty officer frequently did not record a diagnosis. Where recorded, diagnoses were usually correct.

Table 1 Ages of patients dying in each department*

\begin{tabular}{lrcc}
\hline Hospital & 1 & 2 & 3 \\
\hline Total new patients & 42000 & 49000 & 49000 \\
Deaths in A\&E & 20 & 29 & 14 \\
Ages (years) & & & 1 \\
$0-20$ & & 1 & 1 \\
$21-30$ & & 1 & 2 \\
$31-40$ & 1 & 1 & 2 \\
$41-50$ & 10 & 2 & 1 \\
$51-60$ & 4 & 5 & 7 \\
$61-70$ & 4 & 10 & \\
$71-80$ & 1 & 8 & 60.8 \\
$81-90$ & $72 \cdot 6$ & 1 & $0 \cdot 25$ \\
$91+$ & $0 \cdot 45$ & $70 \cdot 8$ & \\
Mean age (years) & & $0 \cdot 59$ & \\
Deaths per thousand new attenders & & & \\
\hline
\end{tabular}

*Mean: 0.45 deaths/1000 new patients.

Table 2 Causes of death

\begin{tabular}{lrcc}
\hline Hospital & 1 & 2 & 3 \\
\hline Cause of death & 14 & 16 & 5 \\
Myocardial infarction/Ischaemic heart disease & 2 & 2 & 3 \\
Chest infection & 2 & - & - \\
Carcinoma & 1 & 1 & 1 \\
Stroke & 1 & - & 1 \\
Not known & - & 5 & 3 \\
PV bleeding (cancer of cervix) & 0 & 2 & - \\
Multiple injuries & - & 1 & - \\
Aortic aneurism & - & 2 & - \\
Pulmonary embolus & - & 29 & 14 \\
Motor neurone disease & 20 & & 1 \\
Total & 20 & & \\
\hline
\end{tabular}


Table 3 Details of A \& E Management

\begin{tabular}{|c|c|c|c|}
\hline Hospital & 1 & 2 & 3 \\
\hline $\begin{array}{l}\text { Delay before patient seen } \\
\text { by doctor }\end{array}$ & $\begin{array}{c}\text { Mean } 2.8 \mathrm{~min} \\
\text { (range } 0-12 \text { ) } \\
\text { (Not known: } \\
14 \text { cases) }\end{array}$ & $\begin{array}{l}\text { Mean } 12 \mathrm{~min} \\
\text { (range 0-35) } \\
\text { (Not known: } \\
0 \text { cases) }\end{array}$ & $\begin{array}{c}\text { Mean } 17 \cdot 7 \mathrm{~min} \\
\text { (range } 0-52 \text { ) } \\
\text { (Not known: } \\
\text { three cases) }\end{array}$ \\
\hline Time from arrival to death & $\begin{array}{l}\text { Mean } 55.1 \mathrm{~min} \\
\text { (range 10-140) } \\
\text { (Not known: } \\
\text { two cases) }\end{array}$ & $\begin{array}{l}\text { Mean } 69 \mathrm{~min} \\
\text { (range 16-185) } \\
\text { (Not known: } \\
0 \text { cases) }\end{array}$ & $\begin{array}{l}\text { Mean } 89.4 \mathrm{~min} \\
\text { (range } 35-217 \text { ) } \\
\text { (Not known: } \\
\text { four cases) }\end{array}$ \\
\hline \multicolumn{4}{|l|}{ Casualty Officer Diagnosis } \\
\hline Correct & 7 & 21 & 8 \\
\hline Incorrect & 1 & 6 & 1 \\
\hline Unclear & 12 & 2 & 5 \\
\hline \multicolumn{4}{|l|}{ Decision not to resuscitate } \\
\hline Indicated in notes & 3 & 4 & 2 \\
\hline Implied & 3 & 9 & 3 \\
\hline No decision recorded & 14 & 16 & 9 \\
\hline
\end{tabular}

The records of those dying were all examined by the authors to determine whether the treatment given was appropriate to the clinical condition as described or if death might have been avoided by different management. It is assumed that when a condition was recognized without undue delay, was vigorously and logically treated, but with the patient still dying, that death probably could not have been prevented. Where the authors found treatment was irrational or unreasonably delayed, they have considered possible that death might have been avoided: these cases are listed in Table 4, with the reasons they have considered that management was unsatisfactory. In none of these cases is there a record of a decision being made before death that resuscitation would be inappropriate.

Table 4 Details of inappropriate management

\begin{tabular}{|c|c|c|c|}
\hline Patient no. & Diagnosis & $\begin{array}{l}\text { Time between } \\
\text { admission and } \\
\text { death }\end{array}$ & Fault in management \\
\hline 1 & Lobar pneumonia & $55 \mathrm{~min}$ & $\begin{array}{l}\text { Patient shocked with bradycardia; } \\
\text { no treatment given }\end{array}$ \\
\hline 2 & $\begin{array}{l}\text { Multiple injuries including rib } \\
\text { fracture }\end{array}$ & $2 \mathrm{~h} 18 \mathrm{~min}$ & Delay in intubation \\
\hline 3 & Myocardial infarction & $2 \mathrm{~h} 15 \mathrm{~min}$ & Unnecessary delay in A \& $\mathrm{E}$ \\
\hline 4 & Myocardial infarction & $1 \mathrm{~h} 0 \mathrm{~min}$ & $\begin{array}{l}\text { Mis-diagnosed and sent home; } \\
\text { returned and died in A \& E }\end{array}$ \\
\hline 5 & Ischaemic heart disease & $3 \mathrm{~h} 5 \mathrm{~min}$ & Sent to $\mathrm{X}$-ray and arrested there \\
\hline 6 & Stab wound to chest & $1 \mathrm{~h} 22 \mathrm{~min}$ & Delay in draining chest \\
\hline 7 & Fracture/dislocation cervical spine & $25 \mathrm{~min}$ & Airway obstruction not corrected \\
\hline 8 & Multiple injuries & $2 \mathrm{~h} 37 \mathrm{~min}$ & No $I / V$ fluids given \\
\hline \multicolumn{4}{|c|}{ *Six patients from one hospital, one from each of the other two. } \\
\hline
\end{tabular}




\section{DISCUSSION}

The three hospitals in this survey serve a variety of very different urban areas including inner city, industrial and suburban districts. There are areas with many retired elderly people, but also areas with younger workers and large floating populations with many recent immigrants. The results obtained reflect in part these differences in populations as well as general practitioners and ambulance services: rapid transfer of the critically ill will result in fewer deaths in the ambulance and more deaths shortly after arrival in hospital.

Inevitably, such a survey is incomplete: there were a number of deaths that occurred when a patient arrived on a ward or in an operating theatre shortly after leaving $\mathrm{A} \& \mathrm{E}$. Some of these deaths may have been due to poor management in A \& E. However, the authors have adopted a strict definition of what constitutes a death in the $\mathrm{A} \& \mathrm{E}$ department to enable comparisons to be made between departments. The authors have considered that the role of the A \& E department in dealing with the seriously ill is to resuscitate, establish an initial assessment or diagnosis, and to arrange rapid transfer to an appropriate area of the hospital. Thus, undue delay in the department, while not necessarily directly contributing towards death, nevertheless indicates suboptimal care.

In this survey, the number of deaths in each department is similar with a mean of 0.45 deaths per thousand new attenders per year. The Birmingham survey reported 488 deaths in 5 years in a department seeing 54000 new patients per year (1.8 deaths per thousand new attenders per year). It is not suggested that these figures are comparable on account of differences as to which patients were considered 'alive on arrival' which will appreciably alter the results. The post-mortem findings for most cases reflect the common cause of sudden death in the community and it is probable that frequently death could not have been avoided even with optimal care: indeed, in 24 cases, the casualty officer dealing with the case decided before death that resuscitation would be inappropriate due to known advanced disease, such as motor neurone disease, or other factors.

However, in eight cases, there were identifiable inadequacies or errors and, in these cases, it is possible that death might have been avoided or at least delayed. Table 4 shows that most of the mistakes were due to the neglect of the basic principles of emergency care, such as attention to the airway, correction of hypovolaemia and careful monitoring of patients with cardiac pain.

Thus, patients suspected of having had a recent myocardial infarction should not be sent to the $\mathrm{X}$-ray department: it is safer to request a portable $\mathrm{X}$-ray while the patient is kept under observation with resuscitation equipment at hand. These patients should be rapidly transferred to the coronary care unit as soon as beds are available.

The outstanding factor in these possibly avoidable deaths is the excessive time spent in the department. It may be argued that accident departments are safer places in which to suffer a cardiac arrest than some wards, due to the immediate availability of skilled staff and resuscitation facilities. However, in the cases listed in Table 4, it appears that the seriousness of the situation was not recognized and that, although there was ample time to summon more senior assistance, this was not done, or was done too late.

This reflects the inexperience and immature judgement of junior casualty officers who are mostly within 2 years of qualification. It has previously been noted that these 
doctors often feel poorly trained in the management of major trauma and find difficulty in taking decisions in such cases (Yates \& Wakeford, 1983). None of the hospitals in this survey operates a 'trauma team'. Such a team might have saved lives by providing $\stackrel{\mathbb{D}}{\mathrm{D}}$ experienced help at an early stage (Spencer, 1985).

The differences in performance between the hospitals participating in this study has led to an examination of the way in which ill patients are managed, with a view to improving standards where deficiencies have been shown.

A prolonged time spent in the department is a feature of almost all cases, including those in which it was decided that resuscitation would be inhumane due to severe chronic disease. These patients commonly spend $1-2 \mathrm{~h}$ in the surroundings of a busy casualty department; it is surely preferable and more dignified that they should be nursed in a quiet sideroom. Delays of an hour or more may be considered acceptable for those with minor complaints, but it should be possible to avoid the usual delays in finding hospital beds for the most seriously ill.

A survey such as this to identify deaths occurring in an A \& E department is a simple form of audit of the care received by the most seriously ill patients. It allows comparison $N$ to be made between departments and identifies areas where improvements are desirable.

\section{ACKNOWLEDGEMENTS}

We thank Mr R. A. Warren, Mr S. S. Tachakra and Mr T. P. Welch for the $\vec{\oplus}$ encouragement and for permitting us to present details of patients in their departments

\section{REFERENCES}

Shalley M. J. \& Cross A. B. (1984) Which patients are likely to die in an accident and emergency department? British Medical fournal 289, 419-21.

Spencer L. D. (1985) Why do our hospitals not make more use of the concept of a trauma team? British Medical fournal 290, 136-8.

Yates D. W. \& Wakeford R. (1983) The training of junior doctors for accident and emergency work: a case for urgent treatment? Injury 14, 456-60. 